\title{
Studies on the Moral Issues of Post-90s' College Students and its Reflections
}

\author{
Yang Zhong yan \\ Feixian Campus, Linyi University \\ Linyi, Shandong, China \\ fxsfyzy@126.com
}

\begin{abstract}
As an important part of the socialist moral education, personal moral education has an important role in promoting the development of social morality. Since the post-90s' college students are the country's precious talent resources, as well as the future of the motherland, their personal qualities are vital to the realization of the Chinese dream, meanwhile, the development of the society would also affect the growth of the post-90s' college students. So far, few studies has concerned about the social morality consciousness and integrity of the students' personal morality, which should be based on the joint efforts of the society, schools, families and college students to seek countermeasures to improve their personal qualities.
\end{abstract}

Keywords- post-90s ; college students; personal qualities; moral issues; reflections

College students are the country's precious talent resources, which is one of the important factors to realize the Chinese dream. General Secretary Xi Jinping pointed out on the Youth Day's speech of 2013 that: "The youth is the leading trend of social power. The civilization of a nation is largely reflected in the moral level and spiritual outlook of the young generation." The college students are the important group of young people, which carries the country and the people's hopes.

Post-90 college students are born in the 1990s; the young generation, which consits of about twenty million college students in China, is the main force of the socialist modernization construction in the 21st Century, and will play a great role in the construction of politics, economy, culture and other fields. Therefore, it is of great significance for the development of the Chinese socialist cause and the great rejuvenation of the Chinese nation. Since the reform and opening up policies have been carried out, China has gradually strengthened the moral construction of citizens; the Party Congress report proposed in strengthening the social morality, ethics, professional ethics, family virtue, individual character of the four aspects to strengthen the construction, personal morality is the important content of social moral construction. Therefore, to strengthen the personal moral construction of the college students is not only the important task of the new era, their personal qualities, which is closely related to the degree of socialist spiritual civilization and the development of a harmonious society, and to the great rejuvenation of the Chinese nation, but also it affects the growth and development of College students.

In modern society, the individual moral character refers to the specific social norms and moral principles which are required by the social production relations or classes and are reflected in the individual's thoughts and actions. Personal morality is the internalization of the individual in the life, which contains the unity of moral cognition, moral emotion, moral will and moral behavior.

"Without virtue out of fashion, people Can't stand without virtue." It can be said that we have more than any time in history to complete the Chinese nation's great rejuvenation of the Chinese dream, which endows the 90 students with more responsibilities, greater glories and missions. There are hundreds of thousands of young people with the whole process in two hundred years to achieve the goal, and so do the post-90s college students to make contributions to the broader arena and make the dream come true. For this reason, it is more needed to improve their personal qualities.

\section{TO STRENGTHEN THE SIGNIFICANCE OF THE} INDIVIDUAL MORAL EDUCATION OF THE POST-90S

\section{A. It is conducive to follow the heritage of the Chinese nation's traditional virtues}

At present, with the continuous development of economic globalization and political multi polarization, the connections among countries have become more closer than ever before. Many developing countries, in the process of modernization, not only introduced advanced culture and ideas in the developed countries, but also tried to promote their own nation's fine traditional virtues. China is a country with a long history, but it also needs to inherit the traditional virtues. Eighteen big report of the party puts forward that: "to rule by law and rule by morality combined, strengthen social morality, professional ethics, family virtues, personal and moral education, carry forward the traditional virtues of the Chinese nation, promoting the era of fresh air. "At present, it is the main body of carrying forward the Chinese traditional virtue, which is the basis of the traditional virtues. Advocated by the traditional virtues of the Chinese nation "Gewu, Zhizhi, sincerity, is heart, self-cultivation, regulating the family, country, the world is flat" achieve the ideal of life balance mode is an important resource for the individual morality education. The Post-90 college students are the future and hope of the nation, , the builders and successors of the socialist cause, therefore, it is urgent to strengthen the traditional virtues of college students personal moral education, and to improve their personal moral cultivation, so that they become the traditional virtues of the Chinese nation in the driving force. 


\section{B. It is conducive to promote the construction of Post- 90s College Students' moral system}

After the research on the construction of individual moral character of college students, it can be said that it is a further supplement and improvement to the college students' moral construction system. In the past, researchers often neglect the education of their personal qualities in the moral education of college students. In fact, the moral education of college students Can't be separated from the personal moral education, personal morality and family virtue, social morality, professional ethics and the mutual support. In college students' moral construction system, to increase the content of personal moral construction, the cultivation of College Students' moral character is more practical and scientific.

\section{It is conducive to promote the comprehensive and harmonious development of College Students}

Marx claimed that the highest value of social development is to achieve the full and harmonious development of people. Morality is one of the most basic qualities of a person, and is an indispensable condition to realize the harmonious development of man. Similarly, college Students' personal morality construction is an important part of the overall harmonious development of college students. The purpose of personal moral education is to set up a noble moral sentiment, promote people's self perfection and self enhancement so as to realize the full and harmonious development of people. At present, the post-90 college students living in a comprehensive transformation of society, are facing various social contradictions and social conflicts, together with the situation of mutual integration, which only strengthen their personal moral construction, improve their personal qualities in order to firmly adhere to the socialist moral high ground and have a strong personality, can improve their self evaluation, self education, and thus promote their full and harmonious development.

\section{It is conducive to promote the harmonious development of society}

As the development strategy of our country, the sixteen major parties will build a harmonious society, A socialist harmonious society, that embodies the democracy and the justice of law, fairness, honesty and friendship, which is full of vigor and vitality, stability and order, reflecting harmony between man and nature. It is a social mutual integration of a rule of law and rule of morality. As a member of society, everyone must abide by the basic moral behavior standards and norms; otherwise, the society will be in chaos. Post 90 college students, as the future of China, has become an indispensable force in building a harmonious society, and actively enterprising, willing to contribute to the community of college students will become a good social habits of the leading and internal promoters. To strengthen the construction of individual moral character of college students can cultivate the spirit of unity and cooperation, so that they can take social responsibilities, so as to promote the development of socialist harmonious society.

\section{THE MAIN PROBLEMS OF POST 90 COLLEGE STUDENTS IN THEIR PERSONAL QUALITIES}

In general, the whole moral level of post 90 students in higher level, they have deep love for life, truth and beauty, and are willingly to actively participate in the moral practice. But in the individual character of college students, their personal qualities are pessimistic, there are still a lot of problems, mainly in the following areas:

\section{A. little social ethics consciousness, few social responsibilities}

Post 90 college students have a strong inspiration for self - consciousness, they are very much enthusiastic in the self - existence and self - development. They hope to grow up in a good environment, but they have a sense of social morality and lack public responsibility. For example, on the campus, they do not know how to protect public campus environment, random damage school property, litter waste phenomenon still exists, "desk culture", "toilet culture" are not uncommon, being late for class and early to leave, class whispering, sleeping, playing phone have occurred, lack of sense of responsibility, lack of adherence to the basic moral obligation.

\section{B. over-concerned with their own interests, lacking lofty ideals and beliefs}

post 90 college students are the only child of their families, the parents care and love in the growing up, coupled with the integration of the world economy has led to a different outlook on their lifes, values and moral values, to the people's ideas and behavior has been a huge impact, so that some students lack lofty ideals and beliefs, they despise the noble moral ideal, self-centered, advocate personal first. They are mainly reflected in the following aspects:

First, individual students are not gregarious. on the campus, we often found that some students have no contact with anyone, not gregarious. According to the survey, they do not gregarious greatly because they pay too much attention to their own interests, students ignore the legitimate rights and interests, selfish, and it is difficult to establish good relationships with classmates. For example, one of the difficult problems in the management of college students is that the students need to change their dormitories. And the reason for the students in the dormitory is that some students can't get along with other students because of their excessive attention to their own interests.

Second, occupying seat is seriously. Every room on, the eve of the exam, the public university libraries, is overcrowding. Some of the students in these places are not open before the door waiting for the door waiting for the seats; some students take five or six seats, only sitting one, the rest of the bags, stationery and other things, which simply ignores other students who Can't find a seat.

Third, Thanksgiving is consciousness. Some students do not understand, appreciate their parents, for their own life, about luxury, extravagant, free money. A survey found that many students consumption were in more than 1000 yuan per month; some students rarely call their parents, while phone is nothing more than ask their parents for money; some students don't understand the teacher's good intentions cherished, sincere teachings to the teacher 
showed repulsion, weariness; individual students towards society, give others help, aid show indifference and selfishness.

\section{C. weak will, lacking the courage to face setbacks}

post 90 college students generally have poor moral character, the main performance in the will are not strong, fear of failure, dare not to face setbacks. They generally have a higher status in the family, almost everything can be met, even if doing something wrong rarely severe blame; their psychological quality in general is not good, frustration is not looking for their own reasons, positive efforts to solve the problem, but give up on themselves, to shirk responsibility, and lack the courage to face setbacks. They are often only negative to think of a way, but the results are often still fail, this to them blow, this time they tend to anxious restless, autistic apathetic and depressed not hair, self withdrawal and lack of indomitable burning, with difficulties to overcome various difficulties.

\section{D. moral behaviors, the lack of moral practice}

Moral behavior is under the control of moral consciousness, through moral practice. post-90 college students' subjective consciousness is generally strong, but the influence of family factors, such as the only child, the school's personal moral education, they are willing to invest in social activities, but lack practical experience, and can not accumulate experience, resulting in moral behavior deviation. For example, they have environmental awareness, but still litter, spitting; they have public morality, but still make loud noise in public places, arbitrary destruction of public property, there is a phenomenon of moral cognition and moral behavior is in conflict.

\section{E. moral quality is not sound, lack of integrity}

The lack of honesty and credit is the typical moral character of the college students in the 1990s. they can be seen in the follows:

First, the examination cheating Can't be avoided. Some students ignore the school rules, cheating in the exam. Cheating Gaoming, by past peek, entrainment, exchange papers, whisper to use high-tech means of communication, cheating psychology from previous nervous and shy become calm.

Second, plagiarism, slip by. In Colleges, students' homework and papers should be independently thought and completed. But some students not to copy others' homework, is to use the network to collect data and find a few articles related to the patchwork when dealing with troubles.

Third, the arrears of tuition and student loans. Many college students are not because of family financial difficulties and tuition arrears, but without the parents for tuition fees for the purchase of high-end mobile phones, computers, and even unable to timely payment of tuition fees; some malicious arrears, money does not pay; some students to obtain loans, family economic status false, counterfeit proof of poverty; some loans for the poor students credit awareness is low, not in accordance with the provisions of schedule owing on the loan.

\section{STRENGTHENING THE POST 90S COLLEGE STUDENTS' PERSONAL MORALITY CONSTRUCTION}

\section{A. improving the social environment for 90 college students' Moral Education}

1) to strengthen the construction of personal moral education system

Individual moral education should not only in the actual educational environment to give up, it should also establish a corresponding guarantee system. On the one hand, to the system to clear, specific and clear way to express, make students in the individual moral confusion, can distinguish between truth from falsehood. On the other hand, it should be a system of individual moral sublimation, through all kinds of media to actively promote the formation of a good social norms, so that it can play a multiplier effect in the cultivation of personal qualities.

\section{2) to purify network environment}

At present, the network has become an indispensable part of the post-90s college students life, there are quite a few students addicted to the Internet, some even play truant to the Internet. the network is full of pornography, violence, reactionary, and many Internet bad information, these will have a bad effect on College Students' thoughts, so the urgent need to strengthen the network supervision departments, purify the network environment. At the same time, we can actively establish the network position, the initiative to attract college students to use the network. We can through the micro Bo, micro channel and Fetion and other tools, the active construction of network education platform, released learning, counseling, employment and other college students pay attention to information can also be through the establishment of websites, forums, correct and positive guidance to college students, so that students can be in a healthy growth.

\section{B. to strengthen the school to 90 students of moral education}

1) establishing the moral education as the first educational thought

We should set up the education for this, moral education for the first school idea, the moral education for the first implementation of the school education teaching process. Strictly implement the relevant spirit of the state, the CPC Central Committee and the State Council on Further Strengthening and improving the ideological and political education of college students, "the CPC Central Committee and the State Council on Further Strengthening and improving the ideological and moral construction of minors," and other documents, the implementation of full education, full education and all-round education. In the establishment of the goal, to the students' Ideological and moral construction in the first place.

\section{2) to establish full education systems}

Full education in the moral education is the premise of the first, to play the whole school effectiveness, and to launch and require the staff to carry out education, service education, management education and teaching all into the school personnel training program, the formation of school leaders, teachers, administrators, service personnel and students themselves to participate in the pattern. All faculty and staff are responsible for the education of their 
own identity and work to position, adjust the work style and methods to promote the formation of a good school atmosphere, to provide better education environment.

3) to focus on mental health education

The school should open the compulsory course of mental health education, play the main channel and the main position in the classroom. According to the problems of college students, the students will hold various mental health education lectures and reports. To carry out mental health survey, to develop a scientific mental health measurement program, through regular psychological measurement, the measurement results will be statistically, the establishment of mental health records, a targeted for college students or individuals to intervene in the psychological problems. In addition, psychological counseling and counseling should be carried out to improve the mental health of college students, and to provide support for the work of individual moral education.

\section{C. to improve the effectiveness of family moral education for College Students}

First, to change the concepts of family education. The family of post-90 students must change has been heavy intellectual light of moral education concept of family education, pay attention to the family influence on the students good moral cultivation, the cultivation of university students' moral character as the core content of family education, on college students were zunlaoaiyou, Honor thy father and thy mother, thrift etc. traditional family virtue education.

Second, schools should pay attention to the family moral education in orderto help parents do their children's moral education work. Schools should strengthen contact with the family, the moral situation of college students in a timely manner to the parents, so that parents have a grasp of the moral development of their children, the moral education of children.

Again, it is very important to improve the way of family moral education, and the scientific nature of education. To treat their children in a democratic way, respect for their children's personality, in order to accommodate, trust the attitude of children, to develop their children's self-confidence, self-esteem and sense of achievement.

Fourth, parents of students in the process of moral education of the children should pay attention to speeches and actions, leaded by example, self-discipline, play an exemplary role model.

\section{D. to promote college students to carry out personal moral education}

1) To form correct moral cognition. College students to take the initiative to understand and grasp the ethics of each field of the society, the concept of honor and disgrace, clear right and wrong; to be good at learning, diligent in thinking, active practice, trying hard to grasp and use new ideas, new knowledge and new experiences; through study and practice activities, the formation of correct moral cognitive standard, and constantly improve the level of their own moral cognition.

2) to cultivate positive moral characters. College students to ongoing moral emotion experience, stimulate moral feelings of sublimation; should be good at listening to the voice of the inner world, constantly enrich and cultivate their morality; to learn, "cautiousness", even in the case of unsupervised, and consciously according to certain moral standards about their own bundles, forming positive moral emotion.

3) To hone tough will. College students should dare to face a variety of complex social phenomenon, overcome all kinds of difficulties in practice, form a strong will; should be good at from a small start, start from around things, perseverance adhere to good deeds; to strict demands on themselves, cultivate indomitable strong willpower and the realization of moral self transcendence.

4) To promote the noble moral behaviors. College students should conscientiously practice the socialist concept of honor and disgrace, take the lead in promoting the socialist ethics, and actively participate in various social practices and public welfare activities, take the initiative to undertake social responsibilities and social obligations, and actively participate in the school organization's learning activities, learning, and promote the party's line, principles, policies, clear their shoulders the historical mission, and constantly enhance their own moral self-cultivation, improve noble moral behavior.

\section{REFERENCES}

[1] Xin Ziqiang, Chi Liping. social change in the young [M].Beijing Normal University press. 2008.

[2] zeng can. University of [M]. far away press.2006.

[3] Zhou Li, Dai Yujie. The necessity of College Students' self education [J]. China Light Industry Education.2006 edition.

[4] Chen Wanbai, Zhang Yaocan. The principle of Ideological and political education [M]. higher education press. 2001 edition.

[5] Lu Shangiu. On Strengthening College Students' moral construction of $[\mathrm{J}]$. education and teaching research of May .2010 edition.

[6] Huang Shaoling. The education and management of college students in arrears of tuition fees $(\mathrm{J})$. Journal of Harbin Vocational and Technical College. 2008 (5).

[7] Peng Qiufa. Study on the construction of style of study in Colleges and universities and the reform of the examination $(\mathrm{J})$. Journal of East China Institute of Technology: Social Sciences. 2007 (2).

[8] Cao Yufeng, Qin Jian. To carry out the thinking of the moral education of college students (J). Journal of Guangxi University of Finance and Economics. 2007.

[9] Li Lina. Thinking about the way of the construction of College Students' personal morality J. Journal of Hebei University of Technology. 2010.

[10] Cao Hexiu. The research teaching mode of Ideological and political theory in Colleges and universities. Journal of East China Institute of Technology: Social Science Edition. 2006 (4).

[11] Zeng Honghua. Strengthening the construction of individual moral character of college students and its path $(\mathrm{J})$. Journal of Taiyuan City Vocational College. 2009 (9).

[12] Chen Wenjin. Under the condition of social change, the college students' personal morality construction. Shanghai: East China Normal University. 2010.

[13] Du Qingmei. "after 90" College Students' Frustration Education Research [D].[master's Degree Thesis], Taiyuan University of Technology.2011.

[14] Lan Tu. 90 after the value of the students of the value of the characteristics of the employment choice research [D]. Kunming University of Science and Technology. 2010.

[15] Kan Nini, "90" College Students' values of [D]. Nanjing University of Science and Technology. 2010. 
[16] Zhang Xueliang. "after 90" college students interpersonal problems and Countermeasures Research [D]. Northeast Normal University.2010.
[17] Chen Pengfei. "after 90" College Students' awareness of social responsibility to cultivate [D]. Henan Normal University. 2010.

[18] Qi Jieqiang. "after 90" College Students' Ideological and behavioral characteristics research [J]. Xi'an Social Sciences. 2011. 